\title{
Overweight and Obesity in Kaoma and Kasama Rural Districts of Zambia: Prevalence and Correlates in 2008-2009 Population Based Surveys
}

Chola Besa ${ }^{1}$, David Mulenga ${ }^{1}$, Olusegun Babaniyi², Peter Songolo ${ }^{2}$, Adamson S Muula ${ }^{3}$, Emmanuel Rudatsikira ${ }^{4}$ and Seter Siziya ${ }^{1 *}$

${ }^{1}$ School of Medicine, Copperbelt University, Ndola, Zambia

${ }^{2}$ World Health Organization Country Office, Lusaka, Zambia

${ }^{3}$ College of Medicine, University of Malawi, Blantyre, Malawi

${ }^{4}$ School of Health Professions, Andrews University, Berrien Springs, Michigan, USA

\begin{abstract}
Background: Overweight and obesity (overweight/obesity) is associated with hypertension. Low- and middleincome countries are experiencing an obesity epidemic. There is growing evidence that the epidemic is on the increase in urban settings of developing countries. However, there is scanty information on the magnitude of this epidemic and its correlates in rural settings. The objective of the current study was to establish levels of overweight/obesity and its correlates in rural areas of Zambia. Designing interventions based on the correlates for overweight/obesity to reduce its prevalence may in turn lead to a reduction in the prevalence of hypertension.
\end{abstract}

Methods: Cross sectional studies using a modified WHO Stepwise questionnaire were conducted. Logistic regression analyses were used to determine factors that were associated with overweight/obesity. Unadjusted odds ratios (OR) and adjusted odds ratios (AOR) and their 95\% confidence intervals are reported.

Results: Totals of 895 participants from Kaoma and 1198 from Kasama took part in the study. Altogether, 7.6\% of the participants were overweight and $2.5 \%$ were obese, with a combined prevalence of overweight/obesity of $10.1 \%$. Factors that were independently associated with overweight/obesity were sex, education, vegetable consumption, smoking and hypertension. Female participants were $78 \%(\mathrm{AOR}=1.78,95 \% \mathrm{Cl}[1.46,2.17])$ more like to be overweight/ obese compared to males. Participants with secondary or higher education level were $2.04(95 \% \mathrm{Cl}[1.56,2.67])$ times more likely to be overweight/obese compared to participants with lower levels of education. Participants who consumed vegetables 5 to 7 days in a week were $35 \%$ (AOR=1.35, 95\% CI [1.06, 1.72]) more likely to be overweight/ obese compared to participants who ate vegetables less than 5 days in a week. Non smokers were $2.06(95 \% \mathrm{Cl}[1.42$ 2.98]) times more likely to be overweight/obese than smokers. Participants who were non hypertensive were $30 \%$ ( $A O R=0.70,95 \% \mathrm{Cl}[0.59,0.82]$ ) less likely to be overweight/obese compared to participants who were hypertensive.

Conclusions: Prevalence of overweight/obesity was low and this is the time to start instituting interventions to control the obesity epidemic in rural districts of Zambia.

Keywords: Overweight/obesity; Prevalence; Correlates; Rural districts; Zambia

\section{Introduction}

Non-communicable diseases (NCDs) are emerging as an important public health problem in developing countries [1] and their risk factors of overweight and obesity have increased in the last two decades [2] in both developed and developing countries [3]. About $65 \%$ of the world's population lives in countries where overweight and obesity kills more people than underweight [4].

Africa is undergoing nutrition transition that is characterized by coexistence of malnutrition and obesity, with the obesity epidemic affecting first the wealthier populations and later strongly associated with poverty $[5,6]$. It has been argued that this epidemic has occurred because of the increasing affordability of highly refined oils and carbohydrates, and a move away from subsistence farm work to sedentary lifestyles $[5,7,8]$.

Gomes et al. [9] reported the prevalence of overweight and obesity of $11.8 \%$ and $6.8 \%$, respectively, in Mozambique. Meanwhile, Kamoun et al. [10] estimated the prevalence of overweight and obesity at $21.8 \%$ and $12.2 \%$, respectively, in Tunisia, with a higher prevalence of overweight ( $23.6 \%$ vs. $10.2 \%)$ and obesity ( $14.8 \%$ vs. $8.6 \%)$ reported in urban than rural districts. In a meta-analysis in which 28 studies were included, the prevalence of obesity was $10.0 \%$ with urban residents being more likely to be obese than rural residents [11].
Among urban residents in Lusaka, the prevalence of obesity was $14.2 \%$ with $5.1 \%$ of males and $18.6 \%$ of females being obese [12]. Reported correlates for obesity in this study were age, sex, education, smoking and blood pressure. In another study in urban Kitwe in Copperbelt province of Zambia, the prevalence of overweight and obesity was $24.7 \%$ and $16.9 \%$, respectively. In addition of sedentary lifestyles, factors associated with overweight or obese were similar to those reported in Lusaka. Differences in the spectrum of correlates may reflect differences in the rates of unemployment between the two urban populations. No similar studies have been conducted in rural areas of the country.

While obesity prevalence appears to be rising across all low- and middle-income countries, it is not clear what urban-rural difference

*Corresponding author: Seter Siziya, School of Medicine, Copperbelt University, Ndola, Zambia, E-mail: ssiziya@gmail.com

Received December 21, 2012; Accepted March 20, 2013; Published March 22 2013

Citation: Besa C, Mulenga D, Babaniyi O, Songolo P, Muula AS, et al. (2013) Overweight and Obesity in Kaoma and Kasama Rural Districts of Zambia: Prevalence and Correlates in 2008-2009 Population Based Surveys. J Hypertens 2: 110. doi:10.4172/2167-1095.1000110

Copyright: $\odot 2013$ Besa C, et al. This is an open-access article distributed unde the terms of the Creative Commons Attribution License, which permits unrestricted use, distribution, and reproduction in any medium, provided the original author and source are credited. 
Citation: Besa C, Mulenga D, Babaniyi O, Songolo P, Muula AS, et al. (2013) Overweight and Obesity in Kaoma and Kasama Rural Districts of Zambia: Prevalence and Correlates in 2008-2009 Population Based Surveys. J Hypertens 2: 110. doi:10.4172/2167-1095.1000110

may exist [13]. Jones-Smith et al. [14] studied repeated cross sectional data from 37 developing countries and found that in 27 of 37 countries, higher social economic status was associated with higher gains in overweight prevalence, and in 10 of the remaining countries, lower social economic status was associated with higher gains in overweight prevalence. Whilst a study was conducted on the prevalence of obesity among urban Lusaka residents in Zambia, the objective of the current study was to establish levels of overweight/obesity and its correlates in rural areas of Zambia with the view of comparing the findings with those from urban settings. Since higher weight is associated with higher blood pressure [15], control of overweight/obesity would lead to the reduction of the prevalence of hypertension.

\section{Materials and Methods}

The research methods that were used in the current study are similar to those that have been described in similar previous studies $[16,17]$. However, we highlight the methods that were used in the current study.

\section{Study area}

The administrative political structure of Zambia is divided into provinces, districts, constituencies and wards. The Central Statistics Office further subdivides the wards into Census Supervisory Areas (CSAs) that are further subdivided into Standard Enumeration Areas (SEAs). At the time of the survey, Zambia was divided into 9 provinces and 72 districts (Figure 1). Kaoma and Kasama districts were predominantly rural districts with population sizes of 162,568 and 170,929 , respectively [18]. The major economic activity for these districts was subsistence farming.

Kaoma district was one of the 8 districts in Western province. Kaoma had 3 constituencies with a total of 20 wards. Meanwhile, Kasama district was one of the 12 districts in Northern Province. It had 2 constituencies with a total of 15 wards.

\section{Study design}

A cross sectional study using a modified World Health Organization (WHO) global Non Communicable Diseases (NCD) surveillance initiative NCD-STEPwise approach was used in the study [19]. The major difference was in the sampling of participants. While WHO recommended selecting one participant from each selected household, we opted to recruit all persons who were of age 25 years or older in a selected household.

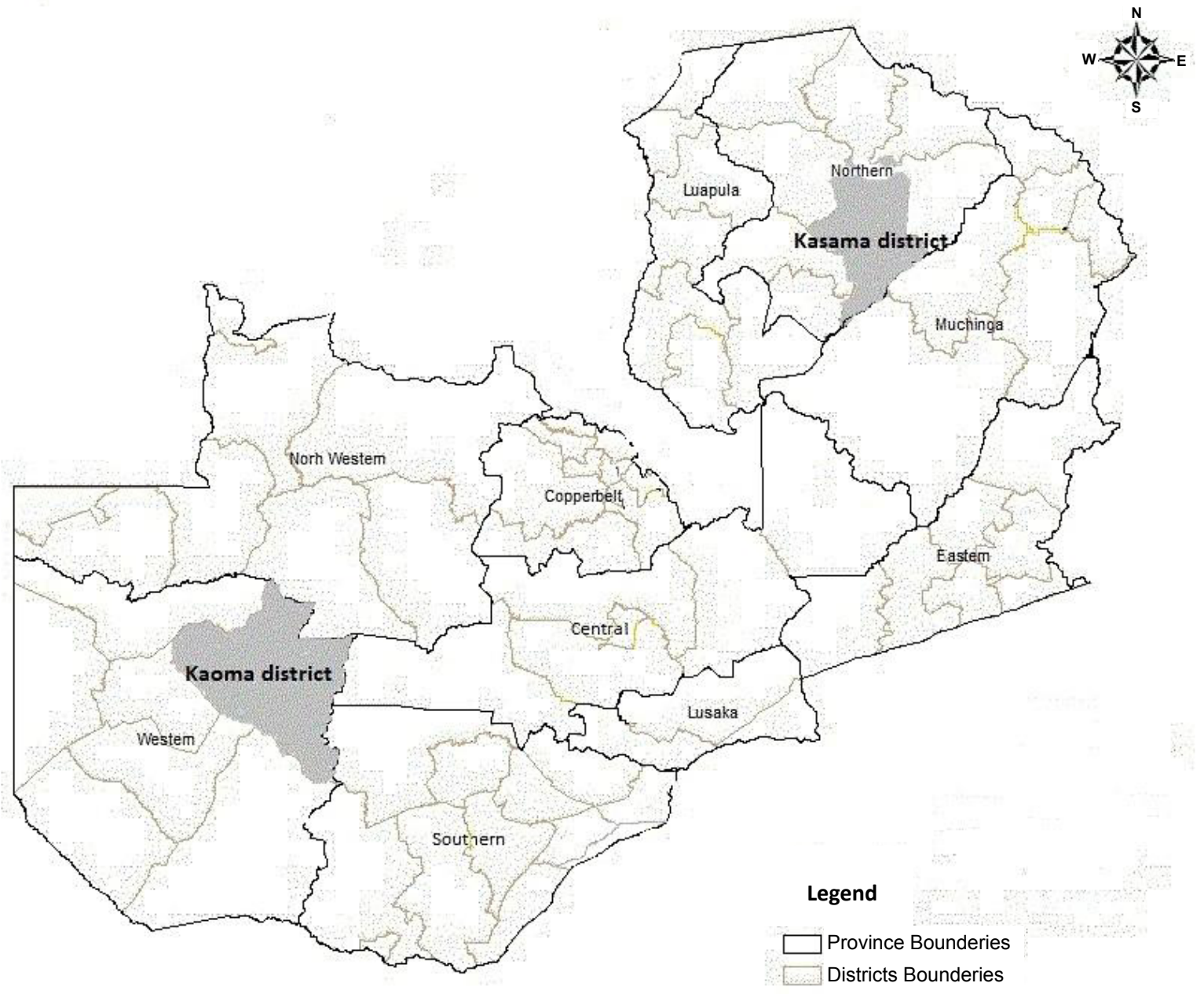

Figure 1: Locations of study sites of Kaoma and Kasama districts in Zambia 
Citation: Besa C, Mulenga D, Babaniyi O, Songolo P, Muula AS, et al. (2013) Overweight and Obesity in Kaoma and Kasama Rural Districts of Zambia: Prevalence and Correlates in 2008-2009 Population Based Surveys. J Hypertens 2: 110. doi:10.4172/2167-1095.1000110

Page 3 of 6

\section{Sample size}

A Statcal program in EPI INFO version 6.04 was used to estimate the sample size. Upon considering a $50 \%$ prevalence rate of the behaviours or indicators considered in the STEPS surveys (as no estimate existed) to be estimated within $5 \%$ (margin of error), 8 age by sex categories [18] and a design effect of 2 , we obtained a sample size of 6128 . After adjusting for $80 \%$ response rate, we obtained a sample size of 7660 . By the end of a series of surveys to be conducted countrywide, we would have recruited 7660 participants. The sample size was proportionally allocated to 8 provinces. The ninth province which was Copperbelt province was excluded from the sampling frame because it was conveniently represented by Lusaka province being the two predominantly urban provinces in the country. The sample size was estimated to produce valid prevalence estimates of the behaviours or indicators considered in the STEPS surveys for each province. After proportionally allocating the sample size of 7660 to the 8 provinces, Kaoma district in Western province was allocated 766 corresponding to the $10 \%$ allocation to the entire sample, and Kasama district in Northern province was allocated 766 corresponding to $11 \%$ allocation to the entire sample. However it became clear after conducting the survey in Lusaka urban district that we would not have enough resources to complete a nation-wide survey. Our immediate thought was to now have a sample size from two rural areas, Kaoma and Kasama, which was similar to the sample size obtained in Lusaka urban district in order to have an efficient study. The sample size for Lusaka was 1915 , and we proportionally allocated a sample size of 2089 to 893 in Kaoma and 1196 in Kasama.

\section{Sampling}

A multi-stage sampling technique was used to sample participants in Kaoma and Kasama districts. In the first stage of sampling, we randomly selected 8 wards in Kaoma; and 6 wards in Kasama. Secondly, Standard Enumeration Areas (SEAs) were proportionally selected with respect to the ward size. Finally, households were systematically sampled from each selected SEA. All persons aged 25 years or older in selected households were eligible to participate in the surveys.

\section{Data collection}

Data collection: A modified WHO STEPwise questionnaire [19] comprising sections on behavioral measurements (Step 1), physical measurements (Step 2) and biochemical measurements (Step 3) was used to collect data. Interviews were conducted at homesteads with some measurements being conducted in private areas of the homestead.

Blood pressure: The Omron Digital Automatic BP Monitor M4-1 (OMRON Healthcare Europe BV, The Netherlands) was used to take blood pressure readings. An average of three readings was considered as the final reading for blood pressure, instead of the recommended averaging of the last two readings.

Height and weight: Height was measured using the Seca Brand 214 Portable Stadiometer (Secagmbh \& Co. kg Hamburg, German) and was recorded in centimetres. Weight was measured in kilograms using the Heine Portable Professional Adult Scale 737 (Secagmbh \& Co. kg Humburg, German). Both height and weight were measured to one decimal place.

\section{Data management}

The Epi Data software was used to enter data by two data entry clerks. The data entry screen had consistency and range checks embedded in it. Data were double entered and validated. The validated data was exported to SPSS version 11.5 for analysis. Further editing was conducted during running of frequencies by checking responses that were out of range.

\section{Definitions}

Body mass Index (BMI) was categorized as $<18.5$ (underweight), 18.5-24.9 (normal weight), 25.0-29.9 (overweight), and 30+ (obese) $\mathrm{kg} / \mathrm{m}^{2}$. The variable education was obtained as the highest level of education and was categorized as no formal schooling, primary (7 years of schooling) and secondary or higher (5 years of schooling/college/ university/postgraduate). The combined prevalence of overweight and obesity (BMI 25+) was termed as overweight/obesity. Participants with blood pressure readings of more than $140 / 90 \mathrm{mmHg}$ were considered to be hypertensive. Participants who were on antihypertensive medication were also included in the high blood pressure group.

\section{Data analysis}

Proportions of the outcome variables and socio-demographic variables were calculated. Bivariate and multivariate logistic regression analyses were conducted. Proportions were compared using the Yates' corrected Chi-square test, and a result yielding a p value of less than $5 \%$ was considered statistically significant. Factors that were statistically significantly associated with the outcome in bivariate analyses were considered in a multivariate logistic regression analysis using a backward variable selection method. Unadjusted odds ratios (OR) and adjusted odds ratio (AOR) with their $95 \%$ confidence intervals (CI) are reported.

\section{Ethical considerations}

The study protocol was reviewed and approved by the University of Zambia Biomedical Research Ethics Committee. Permission to conduct the survey was obtained from the Ministry of Health [Zambia] Informed consent was obtained after the interviewer explained among others the purpose of the study, benefits and risks for taking part in the study to the eligible participants. Entry forms were viewed only by approved study personnel.

\section{Results}

Overall, 2093 participants took part in the surveys: 895 from Kaoma and 1198 from Kasama.

Table 1 shows the distributions of participants' characteristics by sex in each district. The distribution of sex was similar between districts ( $\mathrm{p}=0.262$ ), with $40.3 \%$ of the participants in Kaoma being males and $42.8 \%$ of participants in Kasama being males. Significantly more participants in Kaoma (42.7\%) than Kasama (35.7\%) were of age 45 years or older $(\mathrm{p}=0.002)$ but no significant association was observed between age and district among female participants $(p=0.129)$. Males ( $48.1 \%$ aged 45 years or older) were significantly older than females (38.9\% aged 45 years or older) in Kaoma ( $\mathrm{p}=0.009)$. However, no significant association was observed between age and sex in Kasama $(\mathrm{p}=0.302)$.

Males and females in Kasama were more educated than those in Kaoma $(\mathrm{p}<0.001)$. The proportions of participants who had attained secondary or higher levels of education were $13.1 \%$ in Kaoma and $21.4 \%$ in Kasama. In both districts, males were more educated than females ( 20.5 vs. $9.1 \%$, respectively, $\mathrm{p}<0.001$, in Kaoma; and 33.4 vs. $12.4 \%$, respectively, $\mathrm{p}<0.001$, in Kasama).

Significantly more females than males in both districts ate 
Citation: Besa C, Mulenga D, Babaniyi O, Songolo P, Muula AS, et al. (2013) Overweight and Obesity in Kaoma and Kasama Rural Districts of Zambia: Prevalence and Correlates in 2008-2009 Population Based Surveys. J Hypertens 2: 110. doi:10.4172/2167-1095.1000110

Page 4 of 6

\begin{tabular}{|c|c|c|c|c|c|c|}
\hline & & Kaoma & & & Kasama & \\
\hline & Total & Male & Female & Total & Male & Female \\
\hline Factor & n (\%) & n (\%) & n (\%) & n (\%) & n (\%) & n (\%) \\
\hline \multicolumn{7}{|l|}{ Age group (years) } \\
\hline$<45$ & $481(57.3)$ & $179(51.9)$ & $302(61.1)$ & $728(64.3)$ & $316(62.6)$ & $412(65.7)$ \\
\hline $45+$ & $358(42.7)$ & $166(48.1)$ & $192(38.9)$ & $404(35.7)$ & $189(37.4)$ & $215(34.3)$ \\
\hline \multicolumn{7}{|l|}{ Sex } \\
\hline Male & $357(40.3)$ & - & - & $512(42.8)$ & - & - \\
\hline Female & $529(59.7)$ & - & - & $683(57.2)$ & - & - \\
\hline \multicolumn{7}{|l|}{ Education } \\
\hline None & $257(29.0)$ & $93(26.1)$ & $164(31.0)$ & $164(13.8)$ & $30(5.9)$ & $134(19.7)$ \\
\hline Primary & $512(57.9)$ & $190(53.4)$ & $322(60.9)$ & $772(64.8)$ & $311(60.7)$ & $461(67.9)$ \\
\hline Secondary or higher & $116(13.1)$ & $73(20.5)$ & $43(9.1)$ & $255(21.4)$ & $171(33.4)$ & $84(12.4)$ \\
\hline \multicolumn{7}{|l|}{ Body Mass Index } \\
\hline$<18.5$ & $208(23.7)$ & $84(23.8)$ & $124(23.6)$ & $270(22.8)$ & $150(29.6)$ & $120(17.8)$ \\
\hline $18.5-24.9$ & $585(66.6)$ & $246(69.7)$ & $339(64.4)$ & $790(66.8)$ & $340(67.1)$ & $450(66.7)$ \\
\hline $25.0-29.9$ & $66(7.5)$ & $18(5.1)$ & $48(9.1)$ & $91(7.7)$ & $15(3.0)$ & $76(11.3)$ \\
\hline $30+$ & $20(2.3)$ & $5(1.4)$ & $15(2.9)$ & $31(2.6)$ & $2(0.4)$ & $29(4.3)$ \\
\hline \multicolumn{7}{|l|}{ Ate vegetables (days) } \\
\hline $0-4$ & $148(16.7)$ & $85(23.9)$ & $63(11.9)$ & $226(19.0)$ & $128(25.1)$ & $98(14.4)$ \\
\hline $5-7$ & $736(83.3)$ & $270(76.1)$ & $466(88.1)$ & $963(81.0)$ & $381(74.9)$ & $582(85.6)$ \\
\hline \multicolumn{7}{|l|}{ Ate fruits (days) } \\
\hline $0-4$ & $304(34.4)$ & $144(40.6)$ & $160(30.3)$ & $562(47.8)$ & $271(54.1)$ & $291(43.1)$ \\
\hline $5-7$ & $579(65.6)$ & $211(59.4)$ & $368(69.7)$ & $614(52.2)$ & $230(45.9)$ & $384(56.9)$ \\
\hline \multicolumn{7}{|c|}{ Time usually spent sitting or reclining on a typical day (hours) } \\
\hline$<3.5$ & $375(42.6)$ & $142(40.1)$ & $233(44.3)$ & $576(48.2)$ & $262(51.2)$ & $314(46.0)$ \\
\hline $3.5^{+}$ & $505(57.4)$ & $212(59.9)$ & $293(55.7)$ & $618(51.8)$ & $250(48.8)$ & $368(54.0)$ \\
\hline \multicolumn{7}{|l|}{ Alcohol } \\
\hline Yes & $272(30.8)$ & $173(48.7)$ & $99(18.8)$ & $469(39.9)$ & $291(58.2)$ & $178(26.4)$ \\
\hline No` & $611(69.2)$ & $182(51.3)$ & $429(81.3)$ & $706(60.1)$ & $209(41.8)$ & $497(73.6)$ \\
\hline \multicolumn{7}{|l|}{ Smoke } \\
\hline Yes & $198(22.4)$ & $141(39.6)$ & $57(10.8)$ & $256(21.5)$ & $207(40.4)$ & $49(7.2)$ \\
\hline No & $687(77.6)$ & $215(60.4)$ & $472(89.2)$ & 937 (78.5) & 305 (59.6) & $632(92.8)$ \\
\hline \multicolumn{7}{|l|}{ Hypertension } \\
\hline Yes & $228(25.8)$ & $98(27.5)$ & $130(24.6)$ & $360(30.3)$ & $160(31.3)$ & $200(29.5)$ \\
\hline No & $656(74.2)$ & $258(72.5)$ & $398(75.4)$ & $830(69.7)$ & $351(68.7)$ & $479(70.5)$ \\
\hline
\end{tabular}

Table 1: Socio-demographic and overweight/obesity characteristics of the sample stratified by district.

vegetables and fruits for 5-7 days in a typical week. However, no significant associations were observed between times usually spent sitting or reclining on a typical day and sex in both districts. Twice as many males as females drank alcohol during the previous 30 days to the survey in both districts ( $48.7 \%$ of males vs. $18.8 \%$ of females in Kaoma and $58.2 \%$ of males vs. $26.4 \%$ of females in Kasama). About 4 in 10 of males in Kaoma (39.6\%) and Kasama (40.4\%) smoked cigarettes compared to $10.8 \%$ of females in Kaoma and $7.2 \%$ of females in Kasama. No significant associations were observed between hypertension and sex in both districts.

Among participants in Kaoma, 7.5\% of them were overweight and $2.3 \%$ were obese. Meanwhile, $7.7 \%$ of participants in Kasama were overweight and $2.6 \%$ were obese. There were no significant differences in the proportions of participants who were overweight $(\mathrm{p}=0.976)$ and obese $(\mathrm{p}=0.700)$ between Kaoma and Kasama. Overall, $158(7.6 \%)$ of the participants were overweight and $51(2.5 \%)$ were obese. Because of small numbers, further analysis was combined across overweight and obese. Furthermore, because of no significant differences between Kaoma and Kasama in terms of the proportions of overweight and obese, further analysis was combined across the two districts. Altogether, 209 (10.1\%) out of 2073 participants were overweight/obese.

In bivariate analyses (Table 2), sex, education, vegetable consumption, alcohol consumption, smoking and hypertension were significantly associated with overweight/obesity. However, in multivariate analysis (Table 2), only alcohol consumption was no longer significantly associated with overweight/obesity. Female participants were $78 \%$ (AOR=1.78, 95\% CI $[1.46,2.17])$ more likely to be overweight/obese compared to males. Participants with secondary or higher education level were 2.04 (95\% CI $[1.56,2.67])$ times more likely to be overweight/obese than participants with up to primary level of education. Participants who consumed vegetables 5 to 7 days in a week were $35 \%(\mathrm{AOR}=1.35,95 \% \mathrm{CI}[1.06,1.72])$ more likely to be overweight/obese than participants who ate vegetables less than 5 days in a week. Non smokers were 2.06 (95\% CI $[1.42,2.98])$ times more likely to be overweight/obese than smokers. Participants who were non hypertensive were $30 \%$ ( $\mathrm{AOR}=0.70,95 \% \mathrm{CI}[0.59,0.82])$ less likely to be overweight/obese than participants who were hypertensive.

\section{Discussion}

The prevalence for overweight or obesity in the two rural areas of Zambia was $10.1 \%$ (7.6\% were overweight $2.5 \%$ were obese). This finding accords that of Walker et al. [20] who reported that among indigenous sub-Saharan Africans, obesity was generally low at $1-5 \%$, increasing in populations like Botswana, Namibia and Zimbabwe that experienced a rise in socio-economic status, urbanization, and diminishing physical 
Citation: Besa C, Mulenga D, Babaniyi O, Songolo P, Muula AS, et al. (2013) Overweight and Obesity in Kaoma and Kasama Rural Districts of Zambia: Prevalence and Correlates in 2008-2009 Population Based Surveys. J Hypertens 2: 110. doi:10.4172/2167-1095.1000110

Page 5 of 6

\begin{tabular}{|c|c|c|}
\hline Factor & OR $(95 \% \mathrm{Cl})$ & AOR (95\% Cl) \\
\hline \multicolumn{3}{|l|}{ Age group (years) } \\
\hline$<45$ & 1 & - \\
\hline $45+$ & $1.08(0.93,1.25)$ & \\
\hline \multicolumn{3}{|l|}{ Sex } \\
\hline Male & 1 & 1 \\
\hline Female & $1.83(1.53,2.18)$ & $1.78(1.46,2.17)$ \\
\hline \multicolumn{3}{|l|}{ Education } \\
\hline None & 1 & 1 \\
\hline Primary & $1.04(0.85,1.27)$ & $0.92(0.74,1.15)$ \\
\hline Secondary or higher & $1.59(1.25,2.02)$ & $2.04(1.56,2.67)$ \\
\hline \multicolumn{3}{|l|}{ Ate vegetables (days) } \\
\hline $0-4$ & 1 & 1 \\
\hline $5-7$ & $1.45(1.15,1.83)$ & $1.35(1.06,1.72)$ \\
\hline \multicolumn{3}{|l|}{ Ate fruits (days) } \\
\hline $0-4$ & 1 & - \\
\hline $5-7$ & $1.04(0.90,1.20)$ & \\
\hline \multicolumn{3}{|c|}{ Time usually spent sitting or reclining on a typical day (hours) } \\
\hline$<3.5$ & 1 & - \\
\hline $3.5+$ & $0.98(0.85,1.13)$ & \\
\hline \multicolumn{3}{|l|}{ Alcohol } \\
\hline Yes & 1 & - \\
\hline No’ & $1.49(1.25,1.77)$ & \\
\hline \multicolumn{3}{|l|}{ Smoke } \\
\hline Yes & 1 & 1 \\
\hline No & $2.63(1.87,3.68)$ & $2.06(1.42,2.98)$ \\
\hline \multicolumn{3}{|l|}{ Hypertension } \\
\hline Yes & 1 & 1 \\
\hline No & $0.80(0.69,0.93)$ & $0.70(0.59,0.82)$ \\
\hline
\end{tabular}

OR Unadjusted odds ratio

AOR Adjusted odds ratio

$\mathrm{Cl}$ Confidence interval

Table 2: Factors associated with overweight/obesity in bivariate and multivariate analyses.

activity. The observed level of obesity in the current study is much lower than what was observed in an urban Lusaka district, Zambia, of $14.2 \%$ [12]. Our observation is similar to that made in a systematic review of literature that prevalence of obesity was higher in urban than rural areas in the African continent [21]. The prevalence of overweight or obese in the current study is half the prevalence of overweight (18\%) and obese (5.3\%) reported in Eastern Uganda [22].

Sex, education, vegetable consumption, smoking and hypertension were significantly associated with overweight/obesity. The finding that females were more likely to be overweight/obese supports the assertion by Prentice [5] that obesity is culturally accepted as a positive and desirable trait especially among women, leading to major gender differences in obesity rates in many countries in Africa and some areas of the Pacific. Abubakari et al. [11], in a meta-analysis, found that women were more likely to be obese than men in Western African populations. Elsewhere in Africa, obesity was markedly higher in females than males in Morocco [23], Tanzania [24], South Africa [25] and Zambia [12].

Education level was positively associated with overweight/obesity in the present study. The association between higher education levels with overweight/obesity accords the result found in urban Lusaka district that persons with no formal education were less likely to be obese compared to person who attained college or university level of education [12]. This finding accords the observation by Monteiro et al. [26] that in low-income countries, the risk of obesity among women in the fourth quartile of years of schooling was higher than in the rest of the quartiles of years of schooling, contrary to the observed relationship between obesity and education in the upper-middle-income where a negative relationship was observed.

Findings on the associations between vegetable consumption and overweight/obesity have not been consistent. The finding in the current study that vegetable consumption was associated with overweight/ obesity is not clear. While we did not obtain information on the type of vegetables eaten by participants, most families in Zambia consume green leafy vegetables that have low glycemic index; hence, the results in the current study would be unexpected. Field et al. [27] did not observe any consistent evidence that vegetable, with or without potato products, promoted weight gain. Pérez [28] found that the frequency of eating vegetables was positively related to not being overweight. Vanasse et al. [29] reported that low fruit and vegetable consumption were both good predictors of obesity.

Rudatsikira et al. [12] found that persons who smoked cigarettes in Lusaka, Zambia, were less likely to be obese, and this finding is similar to that reported in the current study of non smokers being more likely to be overweight or obese. In a national cohort, Williamson et al. [30] observed that smoking cessation led to weight gain. Bamia et al. [31] reported that smokers had lower mean body weight and lower mean BMI, and smokers who quit smoking tended to put on weight [30]. These observations may partly be explained by the fact that smoking increases energy expenditure [32] and might suppress appetite [33].

Large epidemiological studies [34,35] with sample sizes of 1 million 
Citation: Besa C, Mulenga D, Babaniyi O, Songolo P, Muula AS, et al. (2013) Overweight and Obesity in Kaoma and Kasama Rural Districts of Zambia: Prevalence and Correlates in 2008-2009 Population Based Surveys. J Hypertens 2: 110. doi:10.4172/2167-1095.1000110

Page 6 of 6

and 10,000 participants have documented the association between body weight and blood pressure. Prevalence rates of hypertension were $50 \%$ to $300 \%$ higher in persons who classified themselves as overweight as in the non overweight group [34] and in another study, BMI was significantly independently associated with systolic and diastolic blood pressure. Also, prospective studies have shown that obesity increases the risk of developing hypertension [36,37] and weight gain in adult life especially seems to be an important risk factor for the development of hypertension [36,38].

\section{Conclusions}

Prevalence of overweight/obesity was low and this is time to start instituting interventions to control the obesity epidemic in rural districts of Zambia.

\section{Acknowledgement}

We are grateful to the research assistants for the successful surveys and to the participants for their cooperation. The World Health Organization Zambia Country office funded the surveys.

\section{References}

1. Saraf DS, Nongkynrih B, Pandav CS, Gupta SK, Shah B, et al. (2012) A systematic review of school-based interventions to prevent risk factors associated with noncommunicable diseases. Asia Pac J Public Health 24: 733752.

2. Ginter E, Simko V (2008) Adult obesity at the beginning of the 21 st century: epidemiology, pathophysiology and health risk. Bratisl Lek Listy 109: 224-230.

3. Aranceta J, Pérez-Rodrigo C, Serra-Majem L, Bellido D, de la Torre ML, et al. (2007) Prevention of overweight and obesity: a Spanish approach. Public Health Nutr 10: 1187-1193.

4. WHO Media Centre (2012) Obesity and overweight. Fact sheet No.311.

5. Prentice AM (2009) Regional case studies--Africa. Nestle Nutr Workshop Ser Pediatr Program 63: 33-41.

6. Steyn NP, Nel JH, Parker WA, Ayah R, Mbithe D (2011) Dietary, social, and environmental determinants of obesity in Kenyan women. Scand $\mathrm{J}$ Public Health 39: 88-97.

7. Baalwa J, Byarugaba BB, Kabagambe EK, Otim AM (2010) Prevalence of overweight and obesity in young adults in Uganda. Afr Health Sci 10: 367-373.

8. Levitt NS (2008) Diabetes in Africa: epidemiology, management and healthcare challenges. Heart 94: 1376-1382.

9. Gomes A, Damasceno A, Azevedo A, Prista A, Silva-Matos C, et al. (2010) Body mass index and waist circumference in Mozambique: urban/rural gap during epidemiological transition. Obes Rev 11: 627-634.

10. Kamoun M, Hajem S, Imen S, Achour N, Slimane H (2008) Prevalence of obesity and overweight in Tunisia on 2001. Tunis Med 86: 649-652.

11. Abubakari AR, Lauder W, Agyemang C, Jones M, Kirk A, et al. (2008) Prevalence and time trends in obesity among adult West African populations: a meta-analysis. Obes Rev 9: 297-311.

12. Rudatsikira E, Muula AS, Mulenga D, Siziya S (2012) Prevalence and correlates of obesity among Lusaka residents, Zambia: a population-based survey. Int Arch Med 5: 14

13. Popkin BM, Adair LS, Ng SW (2012) Global nutrition transition and the pandemic of obesity in developing countries. Nutr Rev 70: 3-21.

14. Jones-Smith JC, Gordon-Larsen P, Siddiqi A, Popkin BM (2011) Cross-nationa comparisons of time trends in overweight inequality by socioeconomic status among women using repeated cross-sectional surveys from 37 developing countries, 1989-2007. Am J Epidemiol 173: 667-675.

15. Julius S, Valentini M, Palatini P (2000) Overweight and hypertension: a 2-way street? Hypertension 35: 807-813.

16. Goma FM, Nzala SH, Babaniyi O, Songolo P, Zyaambo C, et al. (2011) Prevalence of hypertension and its correlates in Lusaka urban district of Zambia: a population based survey. Int Arch Med 4: 34
17. Siziya S, Rudatsikira E, Babaniyi O, Songolo P, Mulenga D, et al. (2012) Prevalence and correlates of hypertension among adults aged 25 years or older in a mining town of Kitwe, Zambia. J Hypertens 1:105.

18. Central Statistical Office (2003) Summary report for the 2000 census of population and housing. CSO, Lusaka.

19. Padrão P, Damasceno A, Silva-Matos C, Prista A, Lunet N (2012) Physica activity patterns in Mozambique: urban/rural differences during epidemiological transition. Prev Med 55: 444-449.

20. Walker AR, Adam F, Walker BF (2001) World pandemic of obesity: the situation in Southern African populations. Public Health 115: 368-372.

21. Adeboye B, Bermano G, Rolland C (2012) Obesity and its health impact in Africa: a systematic review. Cardiovasc J Afr 23: 512-521.

22. Mayega RW, Makumbi F, Rutebemberwa E, Peterson S, Östenson CG, et al. (2012) Modifiable socio-behavioural factors associated with overweight and hypertension among persons aged 35 to 60 years in eastern Uganda. PLoS One 7: e47632.

23. Tazi MA, Abir-Khalil S, Chaouki N, Cherqaoui S, Lahmouz F, et al. (2003) Prevalence of the main cardiovascular risk factors in Morocco: results of a National Survey, 2000. J Hypertens 21: 897-903.

24. Njelekela M, Kuga S, Nara Y, Ntogwisangu J, Masesa Z, et al. (2002) Prevalence of obesity and dyslipidemia in middle-aged men and women in Tanzania, Africa: relationship with resting energy expenditure and dietary factors. J Nutr Sci Vitaminol (Tokyo) 48: 352-358.

25. Puoane T, Steyn K, Bradshaw D, Laubscher R, Fourie J, et al. (2002) Obesity in South Africa: the South African demographic and health survey. Obes Res 10: $1038-1048$

26. Monteiro CA, Moura EC, Conde WL, Popkin BM (2004) Socioeconomic status and obesity in adult populations of developing countries: a review. Bull World Health Organ 82: 940-946.

27. Field AE, Gillman MW, Rosner B, Rockett HR, Colditz GA (2003) Association between fruit and vegetable intake and change in body mass index among a large sample of children and adolescents in the United States. Int J Obes Relat Metab Disord 27: 821-826.

28. Pérez CE (2002) Fruit and vegetable consumption. Health Rep 13: 23-31.

29. Vanasse A, Demers M, Hemiari A, Courteau J (2006) Obesity in Canada: where and how many? Int J Obes (Lond) 30: 677-683.

30. Williamson DF, Madans J, Anda RF, Kleinman JC, Giovino GA, et al. (1991) Smoking cessation and severity of weight gain in a national cohort. N Engl Med 324: 739-745.

31. Bamia C, Trichopoulou A, Lenas D, Trichopoulos D (2004) Tobacco smoking in relation to body fat mass and distribution in a general population sample. Int $\mathrm{J}$ Obes Relat Metab Disord 28: 1091-1096.

32. Collins LC, Cornelius MF, Vogel RL, Walker JF, Stamford BA (1994) Effect of caffeine and/or cigarette smoking on resting energy expenditure. Int $\mathrm{J}$ Obes Relat Metab Disord 18: 551-556.

33. Filozof C, Fernández Pinilla MC, Fernández-Cruz A (2004) Smoking cessation and weight gain. Obes Rev 5: 95-103

34. Stamler R, Stamler J, Riedlinger WF, Algera G, Roberts RH (1978) Weight and blood pressure. Findings in hypertension screening of 1 million Americans. JAMA 240: 1607-1610.

35. Dyer AR, Elliott $P$ (1989) The INTERSALT study: relations of body mass index to blood pressure. INTERSALT Co-operative Research Group. J Hum Hypertens 3: 299-308.

36. Friedman GD, Selby JV, Quesenberry CP Jr, Armstrong MA, Klatsky AL (1988) Precursors of essential hypertension: body weight, alcohol and salt use, and parental history of hypertension. Prev Med 17: 387-402.

37. Yong LC, Kuller LH, Rutan G, Bunker C (1993) Longitudinal study of blood pressure: changes and determinants from adolescence to middle age. The Dormont High School follow-up study, 1957-1963 to 1989-1990. Am J Epidemiol 138: 973-983.

38. Huang Z, Willett WC, Manson JE, Rosner B, Stampfer MJ, et al. (1998) Body weight, weight change, and risk for hypertension in women. Ann Intern Med 128: 81-88. 